\title{
El euroescepticismo en el Parlamento europeo. Análisis del comportamiento legislativo y político de los diputados euroescépticos de la Cuarta a la Séptima legislaturas (1994-2014). ¿Cambio o continuidad en la Octava legislatura (2014-2019)?*
}

Euroscepticism in the European Parliament. Analysis of the Legislative and Political Behaviour of Eurosceptic Members of the European

Parliament from the Fourth to the Seventh Parliaments (1994-2014).

Change or Continuity in the Eighth Parliament (2014-2019)?

\author{
María Victoria Álvarez \\ Universidad Nacional de Rosario, Argentina
}

\begin{abstract}
Sumario: I. Introducción.-II. El concepto de euroescepticismo y el euroescepticismo en los partidos políticos. - III. El euroescepticismo en el Parlamento Europeo.-IV. El comportamiento legislativo general de los diputados euroescépticos de la Cuarta a la Séptima legislaturas.-V. El comportamiento legislativo por tema de los diputados euroescépticos de la Cuarta a la Séptima legislaturas.-VI. El comportamiento político de los diputados euroescépticos de la Cuarta a la Séptima legislaturas.-VII. El comportamiento legislativo y político de los diputados euroescépticos en la Octava Legislatura: ¿cambio o continuidad?.-VIII. Conclusiones.
\end{abstract}

Resumen: La oposición a la integración europea se ha convertido en una dimensión trascendental en la Unión Europea (UE) en los últimos tiempos. El Parlamento Europeo (PE) constituye un escenario propicio para realizar una investigación sobre el euroescepticismo. Este trabajo versa sobre las posturas críticas y opuestas a la integración europea manifestadas en el comportamiento legislativo y político de los diputados euroescépticos desde la Cuarta a la Séptima legislaturas, distinguiendo entre euroescépticos 'duros' y 'blandos'. También nos interrogamos acerca del posible comportamiento de los diputados euroescépticos en la Octava Legislatura. El hecho de que los partidos euroescépticos difieran en el grado y las razones de su oposición se ve reflejado en diferentes estrategias de acción entre sus representantes en el PE.

* Recibido el 16 de diciembre de 2014, aceptado el 3 de febrero de 2015. 
Palabras clave: Parlamento Europeo, Euroescepticismo, Comportamiento legislativo y político de diputados euroescépticos

Abstract: Opposition to European integration has become an important dimension in the European Union (EU) in recent times. The European Parliament (EP) is an especially auspicious arena for research on Euroscepticism. This paper analyzes the criticism and opposition to European integration expressed in the legislative and political behaviour of Eurosceptic MEPs, distinguishing between the 'hard' and 'soft' types, from the 4th to the 7th Parliaments. We also consider the possible behaviour of Eurosceptic MEPs in the 2014-2019 EP. The fact that Eurosceptic parties differ in the extent and reasons for their opposition towards the EU is reflected in diverse strategies of action among their representatives in the EP.

Keywords: European Parliament, Euroscepticism, legislative and political behavior of Eurosceptic MEPs

\section{Introducción}

La oposición a la integración europea, aunque marginal durante décadas, se ha convertido en una dimensión trascendental del sistema político de la Unión Europea (UE) en los últimos años. Incluso desde los orígenes de la integración en Europa, diversos movimientos y actores se han opuesto a ella. Especialmente desde los años noventa, el euroescepticismo forma parte no sólo de las realidades político-partidarias de los Estados miembros de la UE sino también de la propia dinámica de las instituciones europeas. Esta cuestión es de una relevancia particular en el Parlamento Europeo (PE), una de las asambleas regionales directamente elegidas más poderosas del mundo. ${ }^{1}$

El PE constituye un escenario especialmente propicio para realizar una investigación sobre las fuerzas euroescépticas dado que es la única institución de la UE donde la manifestación explícita de posturas opuestas a la integración europea ha estado presente de forma continua. En cambio, tanto en la Comisión Europea, dado el procedimiento por el cual son elegidos los Comisarios, como en el Consejo, habida cuenta de la esencia cooperativa y diplomática de su labor y las escasas posibilidades de que los partidos fuertemente euroescépticos lleguen a los gobiernos nacionales, la presencia de miembros euroescépticos es algo sumamente inusual.

${ }^{1}$ HIX, S., RAUNIO, T. y SCULLY, R., "Fifty Years On: Research on the European Parliament", Journal of Common Market Studies, Vol. 41, No. 2/2003, p. 192. 
A lo largo de toda la historia del PE, ha habido partidos o facciones partidarias euroescépticas, ${ }^{2}$ pero el traspaso de los euroescépticos de la arena política nacional al PE se manifiesta claramente a partir de la Cuarta Legislatura (1994-1999). Es en 1994 cuando ingresan por primera vez representantes de partidos políticos enfocados esencialmente en un tema: su oposición a la UE ('issue-single parties'). ${ }^{3}$ Esta tendencia, con algunos vaivenes, se ha seguido confirmando en las sucesivas legislaturas.

En las cuatro legislaturas bajo estudio (Cuarta, Quinta, Sexta y Séptima legislaturas), alrededor del $22 \%$ de los miembros del PE (en promedio) fueron euroescépticos (más allá de la manera en que se hayan organizado al interior del mismo). Dos de los grupos euroescépticos de la Séptima Legislatura (2009-2014) han sido reeditados en el actual Parlamento (2014-2019). Sin embargo, con la representación vigente de diputados anti-integración en alrededor del $30 \%$ de la asamblea, este es claramente el PE más euroescéptico que la UE conoce desde las primeras elecciones europeas en 1979.

La paradoja para los diputados euroescépticos en el PE es que, por un lado, en la mayoría de los casos su ideología los compromete a ser críticos vehementes de la UE - inclusive promoviendo directamente la salida de su Estado nacional de la misma-. Pero, por otro lado, se benefician de la UE - obteniendo recursos económicos, representación, legitimidad y contactos $-{ }^{4}$ y son parte de una de sus instituciones fundamentales. Ello implica que estos diputados asisten al Pleno, votan, trabajan en las comisiones parlamentarias, y realizan otras acciones dentro de un contexto institucional cuya existencia y/o legitimidad objetan en mayor o menor medida.

Este trabajo, entonces, gira alrededor del análisis de la forma en que actúan en el PE los diputados que ostentan posiciones críticas u opuestas a la integración europea, teniendo en cuenta que lo hacen dentro de un marco institucional complejo: el PE es una institución supranacional, sus miembros provienen de diferentes partidos políticos nacionales, y, una vez en el

2 Antes de 1979, cuando los miembros del PE eran delegados de los parlamentos nacionales, diferentes fuerzas políticas manifestaron su oposición a la institución parlamentaria: los gaullistas y algunos socialistas radicales franceses, y liberales alemanes y holandeses. Los comunistas - que constituían el 10\% del electorado de los seis Estados miembros en esa época- se opusieron al envío de delegados al PE, al no reconocer a las instituciones comunitarias como legítimas. Posteriormente, diversos partidos euroescépticos accedieron al PE en tres olas: en los años setenta, se añadieron comunistas y conservadores de los países que ingresaron en 1973, a partir de mediados de los ochenta, fuerzas de extrema derecha, y desde 1994, partidos anti-europeos ('single-issue parties'). LECONTE, C., Understanding Euroscepticism, Basingstoke: Palgrave Macmillan, 2010, p. 130.

3 Ibid., p. 130.

${ }^{4}$ MORRIS, M., Conflicted Politicians: the populist radical right in the European Parliament, Counterpoint, Londres, 2013, p. 5. 
mismo, la mayoría de los diputados se organizan en grupos políticos según sus afinidades político-ideológicas y no por nacionalidades, lo que constituye el principio organizacional interno más importante del PE. ${ }^{5}$

Los eurodiputados, de manera individual, cuentan con algún margen de libertad en el ejercicio de sus funciones y la formulación de sus prioridades: deciden, por ejemplo, si asisten o no a las sesiones plenarias, si votan o no, inclusive si quieren formular preguntas orales o escritas al Consejo y a la Comisión, o si desean realizar propuestas de resoluciones o de enmiendas, entre otras. Los diputados euroescépticos, entonces, deben actuar en un contexto institucional altamente complejo que provee cierta capacidad de movimiento, por un lado, y fuertes constreñimientos, por otro. ${ }^{6}$

En este artículo examinamos no sólo el comportamiento legislativo o de votación de los diputados euroescépticos a través del índice de cohesión en votaciones nominales - en forma general y clasificadas por temáticas-, sino que también efectuamos un análisis de lo que denominamos aquí el comportamiento político, es decir, acciones relacionadas con las atribuciones de los diputados distintas de votar, como por ejemplo, participar en comisiones parlamentarias, ser ponentes de informes, tomar parte en los debates en el Pleno, proponer resoluciones, o formular preguntas a instituciones europeas, entre otras.

Los diputados euroescépticos objeto de nuestro estudio ostentan distintos tipos de euroescepticismo, ya que difieren tanto en la visión que tienen sobre Europa como en la forma en que perciben que la UE falla. ${ }^{7}$ Inclusive, pueden oponerse a la UE por razones opuestas. Más aún, el euroescepticismo resulta una noción compatible con diferentes ideologías en el espectro político, que se extiende desde la extrema derecha hasta la extrema izquierda, y hasta forma parte de algunos partidos mayoritarios de centro. Adherimos en este trabajo a la definición de euroescepticismo más amplia-

5 Vid. KREPPEL, A., The European Parliament and Supranational Party System. A Study in Institutional Development. Cambridge University Press, 2002; HIX, S., NOURY, A. y ROLAND, G., Democratic Politics in the European Parliament, Cambridge: Cambridge University Press, 2007; JUDGE, D. y EARNSHAW, D., The European Parliament, Palgrave Macmillan, Basingstoke, 2003, entre otros.

${ }^{6}$ BRACK, N., "Euroscepticism at the Supranational Level: The Case of the 'Untidy Right' in the European Parliament", Journal of Common Market Studies, Vol. 51, No. 1/2013, p. 89.

${ }^{7}$ Los criterios para definir el universo de estudio se basaron en la triangulación y contrastación de diferentes fuentes de datos, principalmente, extensas bases de datos apoyadas, a su vez, en encuestas de expertos que estiman el posicionamiento de los partidos políticos de países europeos respecto de la integración europea. La estrategia de nuestra investigación se centró en un universo de estudio planteado en sentido amplio. 
mente aceptada - originada en la obra de Paul Taggart y Aleks Szczerbiak - que realiza la distinción entre euroescepticismo 'duro' ('hard euroscepticism') y euroescepticismo 'blando' ('soft euroscepticism'). ${ }^{8}$

El objetivo general de nuestra investigación consiste en analizar las tendencias ${ }^{9}$ del comportamiento legislativo y político de los diputados euroescépticos del PE en la Cuarta (1994-1999), Quinta (1999-2004), Sexta (2004-2009) y Séptima (2009-2014) legislaturas, de manera de intentar proyectar el posible comportamiento de los diputados euroescépticos en la actual Octava Legislatura (2014-2019).

Entre los objetivos específicos incluimos: examinar el comportamiento legislativo de los diputados euroescépticos a través del índice de cohesión en votaciones nominales en general (primer objetivo específico); analizar el comportamiento legislativo de los diputados euroescépticos a través del índice de cohesión en votaciones nominales por temas (segundo objetivo específico); y examinar el comportamiento político de los diputados euroescépticos, incluyendo la asistencia a las votaciones (índice de presentismo), la redacción de informes de comisión o rapports (funciones legislativas), la formulación de preguntas escritas (funciones de control), la redacción de propuestas de resolución (poder de deliberación general), y las intervenciones en el Pleno (actividad de debate legislativo) (tercer objetivo específico).

Luego de esta introducción, el artículo avanza algunas consideraciones sobre el concepto de euroescepticismo, particularmente, aquel presente en los partidos políticos. Posteriormente referimos a la dimensión anti/prointegración en el PE, para luego describir los resultados de nuestra investigación respecto al comportamiento legislativo y político de los diputados euroescépticos en el periodo bajo estudio. Logramos arribar a la conclusión de que el hecho de que los partidos euroescépticos difieran en la intensidad de su oposición a la integración europea y en los argumentos que esgrimen para oponerse a ella, se ve reflejado en diferentes estrategias de acción entre sus representantes en el PE.

8 SZCZERBIAK, A. y TAGGART, P., "Theorising Party-Based Euroscepticism: Problems of Definition, Measurement and Causality", SEI Working Paper No. 69 - European Parties Elections and Referendums Network Working Paper No. 12/2003; SZCZERBIAK, A. y TAGGART, P., "Introduction: Researching Euroscepticism in European Party Systems: A Comparative and Theoretical Research Agenda", en SZCZERBIAK, A. y TAGGART, P. (eds.), Opposing Europe? The Comparative Party Politics of Euroscepticism Volume 2 Comparative and Theoretical Perspectives, Oxford University Press, Oxford, 2008.

9 No es aleatorio el uso de la expresión "tendencias" de comportamiento ya que no hallamos patrones rígidos de conducta en todos los casos. 


\section{El concepto de euroescepticismo y el euroescepticismo en los partidos políticos}

El término euroescepticismo es de relativamente reciente cuño. No fue utilizado como tal en las primeras décadas de la integración europea, aunque ello no significó la inexistencia de críticas o dudas desde los momentos inaugurales del proyecto integracionista. Pese a la diversidad de opiniones sobre el lugar y el momento exacto en que el término surgió, ${ }^{10}$ el «euroescepticismo» constituye un concepto derivado del discurso periodístico más que de la Ciencia Política, ${ }^{11}$ lo cual dificulta su definición clara y rigurosa. ${ }^{12}$

En general, en el discurso académico y político actual, así como en el de los medios de comunicación, el término euroescepticismo es equivalente a diferentes formas de oposición a la integración europea. ${ }^{13}$ En nuestro trabajo, suscribimos a una concepción amplia del término según la cual el euroescepticismo expresa dudas o aprensión respecto de la integración europea, manifestado en un amplio espectro de posiciones críticas que incluye la oposición frontal y abierta. ${ }^{14}$

Tal como hemos comentado, el euroescepticismo resulta una noción compatible con diferentes ideologías en el espectro político, que se extiende desde la extrema derecha hasta la extrema izquierda, y hasta forma parte de

${ }^{10}$ Los orígenes del concepto pueden rastrearse en artículos periodísticos escritos por la prensa británica en los años ochenta (VASILOPOULOU, S., "Varieties of Euroscepticism: The Case of the European Extreme Right", Journal of Contemporary European Research, Vol. 5, No. 1/2009, p. 4). Algunos afirman haber hallado el momento preciso en que emergió el término: su primer uso público se habría realizado en un artículo del 30 de junio de 1986 publicado por The Times dedicado a la Primera Ministra británica Margaret Thatcher (HOOGHE, L. y MARKS, G., "Sources of Euroscepticism", Acta Politica, 42/2007, p. 127). Luego el discurso de Thatcher en el Colegio de Europa (Brujas, Bélgica), el 20 de septiembre de 1988, fue considerado como un hito en el desarrollo de la oposición a la integración europea al ser la primera vez que un líder europeo criticaba la dirección tomada por el proceso de integración (USHERWOOD, S. y STARTIN, N., "Euroscepticism as a Persistent Phenomenon", Journal of Common Market Studies, Vol. 51, No.1/2013, p. 3). Otros afirman que el término fue utilizado por primera vez en una publicación de The Economist del 26 de diciembre de 1992. El artículo recurría a este concepto para describir la amarga opinión de los ciudadanos alemanes respecto a la integración europea luego de que Alemania fuera intimada a modificar la pureza de su cerveza para adecuarla a las normas del mercado interno (HOOGHE, L. y MARKS, G., op. cit., nota 10, p. 120).

11 SZCZERBIAK, A. y TAGGART, P., op. cit., 2003, nota 8, p. 6.

12 El término escepticismo por sí solo significa una actitud que se relaciona con la duda o la incredulidad. El término euroescepticismo fue evolucionando alejándose de su vinculación con una actitud neutral para pasar a ligarse con actitudes negativas en torno de la integración europea.

${ }^{13}$ LECONTE, C., op. cit., nota 2, p. 5.

${ }^{14}$ HOOGHE, L. y MARKS, G., op. cit., nota 10, p. 120. 
algunos partidos mayoritarios de centro. No constituye, evidentemente, una ideología única u homogénea. ${ }^{15}$ Más importante aún, los partidos euroescépticos pueden diferir en la intensidad de su oposición a la integración europea y en los argumentos y razones que esgrimen para oponerse a ella.

Sin embargo, confluyen en la crítica hacia el proceso, llegando a proponer, en los casos más extremos, la paralización o disolución del proceso, o la salida de un país miembro; mientras que, en otros casos, los partidos cuestionan los valores en los que se basa el proceso, como la economía de mercado, la libre competencia, y la no-discriminación, así como sus principios, como la cesión de soberanía, la delegación de competencias nacionales a instituciones supranacionales, o la primacía del derecho de la UE sobre el derecho doméstico. ${ }^{16}$

Más que lograr arribar a una definición uniforme y consistente del término, la literatura sobre euroescepticismo partidario se ha concentrado en aplicar diferentes tipologías a los partidos políticos nacionales según su actitud en torno de la integración europea. El debate se ha concentrado en la elaboración de tipos o categorías de euroescepticismo (encontrando tantas tipologías como especialistas dedicados a la temática existen), relegando la insoslayable tarea de consensuar alrededor de una definición unívoca.

Los autores más prolíficos en el tema, Taggart y Szczerbiak, desglosaron originalmente el concepto de euroescepticismo partidario en la distinción entre oposición de principio a la integración europea (euroescepticismo 'duro' o 'hard euroscepticism') y oposición contingente o circunstancial (euroescepticismo 'blando' o 'soft euroscepticism'). ${ }^{17}$ Posteriormente, estos autores reformularon la idea de euroescepticismo 'duro' y 'blando' concentrándose en las actitudes de los partidos políticos en cuanto a la oposición a la cesión o transferencia de competencias soberanas desde los Estados hacia un centro supranacional. En palabras de Szczerbiak $\mathrm{y}$ Taggart, «(...) based on the ceding or transfer of powers to supranational institution such as the EU (Hard); and opposition to the EU's current or future planned trajectory based on the further extension of competencies that the EU is planning to make (Soft)». ${ }^{18}$

15 LECONTE, C., op. cit., nota 2, p. 4.

16 Ibid., p. 8.

17 SZCZERBIAK, A. y TAGGART, P., "Opposing Europe: Party Systems and Opposition to the Union, the Euro and Europeanisation", SEI Working Paper No. 36 - Opposing Europe Research Network Working Paper No. 1/2000, p. 6.

18 SZCZERBIAK, A. y TAGGART, P. op. cit., 2008, nota 8, p. 3. 
Entonces, podemos distinguir entre dos tipos de euroescepticismo partidario. ${ }^{19}$ Por un lado, aquellos partidos que se oponen «por principio» a la integración europea encarnada en la UE, afín al euroescepticismo 'duro', con deseos de descarrilar o paralizar el proceso de la integración europea,$^{20}$ o buscar la salida de un Estado miembro, y que es capaz de criticar duramente algunas políticas «centrales» de la UE. ${ }^{21} \mathrm{Y}$, por otro, aquellos que se oponen, no al sistema político europeo en sí, sino a la trayectoria actual o futura de la UE, en una oposición más limitada o contingente, análoga al euroescepticismo 'blando', y en consonancia con una crítica constructiva al proceso de integración, en un intento por mejorar una o varias instituciones, políticas o prácticas existentes. ${ }^{22}$

\section{El euroescepticismo en el Parlamento Europeo}

El espacio político-partidario del PE está basado en dos dimensiones centrales: además de la tradicional dicotomía izquierda-derecha, también es posible encontrar, aunque en forma subsidiaria, la dimensión de conflicto y coalición en torno de posiciones a favor o en contra de la integración europea y de la UE. ${ }^{23}$ En las últimas décadas las investigaciones han comprobado la estabilización de los grupos euroescépticos en el PE y la persistencia de la división pro/anti-integración dentro de esta institución europea. ${ }^{24}$

19 A los fines de nuestra investigación, hemos utilizado las bases de datos sobre posicionamientos de partidos de la Universidad de North Carolina-Chapel Hill de 1999, 2002 y 2006. Estas bases de datos están disponibles en línea: www.unc.edu/ hooghe. En el tema de "Integración Europea" las bases de Chapel Hill distinguen las posiciones de los partidos entre 1. «anti» integración, 2. neutral y 3. «pro» integración. Por consiguiente, la distinción binaria entre euroescepticismo 'blando' y 'duro' encaja de manera adecuada, aunque admitimos que ambos tipos deberían considerarse como grados o escalas de un continuum (RAY, L., "Mainstream Euroscepticism: Trend or Oxymoron?", Acta Politica, 42/2007, p. 157) teniendo en cuenta la variedad de posiciones que interactúan dentro de la noción global de euroescepticismo.

${ }^{20}$ LECONTE, C., op. cit., nota 2, p. 42

21 SZCZERBIAK, A. y TAGGART, P., op. cit., 2008, nota 8.

22 FLOOD, C., "Euroscepticism: A Problematic Concept". Trabajo presentado en la UACES 32nd Annual Conference and 7th Research Conference, Queen's University Belfast, Septiembre 2002

${ }^{23}$ Vid. RAUNIO, T., "Political parties in the European Union", en JØRGENSEN K. E., POLLACK, M. A. y ROSAMOND, B. (eds.), Handbook of European Union Politics, Sage Publications, Londres, 2007; HIX, S., "Dimensions and alignments in European Union politics: Cognitive constraints and partisan responses", European Journal of Political Research, No. 35/1999, pp. 69-125.

${ }^{24}$ BRACK, N., op. cit., nota 6, p. 85 
Muchos de los diputados euroescépticos presentan un dilema fundamental, al cuestionar en mayor o menor medida a la institución de la que forman parte, o inclusive, al propio sistema político europeo. Si bien entre 1952 y 1979 el método de selección de los diputados al PE (envío de delegados de los parlamentos nacionales) explicaba la «sobre-representación» de diputados con orientaciones favorables a la integración, a partir de las primeras elecciones europeas directas en 1979, pasaron a tener representación un determinado número de diputados que declaraban abiertamente su oposición al proceso de integración. ${ }^{25}$

En efecto, las elecciones al PE representan una arena electoral privilegiada para los partidos euroescépticos. ${ }^{26}$ Los comicios europeos tienen ciertas características, por ser elecciones nacionales de «segundo orden» ('second-order elections' $)^{27}$, que permiten un comportamiento electoral infrecuente. Por un lado, el voto en las elecciones europeas castiga al gobierno nacional de turno; y por otro lado, recompensa a las formaciones minoritarias o alternativas y sirven de plataforma y exhibición de sus reivindicaciones internas. ${ }^{28}$

El proceso de ratificación del Tratado de Maastricht condujo a la emergencia de fuerzas políticas nuevas y reveló la fortaleza del euroescepticismo a lo largo del continente. Las elecciones europeas de 1994 reforzaron la posición del euroescepticismo al interior del PE con la llegada de representantes de partidos anti-UE, y la consiguiente conformación de grupos euroescépticos per se. Desde entonces, el proceso de «constitucionalización» de la UE promovió aún más el euroescepticismo, y las elecciones al PE proveyeron a los grupos euroescépticos un foro para su movilización. ${ }^{29} \mathrm{~A}$ su vez, las últimas ampliaciones de la UE contribuyeron a consolidar las filas de voces disidentes y ampliar el rango de actitudes euroescépticas. ${ }^{30}$

La aparición de estas fuerzas se produjo en una institución donde ha existido una fuerte tendencia por parte de los grupos políticos moderados

${ }^{25}$ BRACK, N. y COSTA, O., "The Role(s) of the Eurosceptic MEPS", en FUCH, D., MAGNI-BERTON, R. y ROGER, A. (eds.), Euroscepticism: Images of Europe among Mass Publics and Political Elites, Barbara Budrich Publishers, 2009, p. 1

${ }^{26}$ LECONTE, C., op. cit., nota 2, pp. 128-129

${ }^{27}$ REIF, K. y SCHMITT, H., "Nine Second-Order Elections: A Conceptual Framework for the Analysis of European Election Results", European Journal of Political Research, Vol. 8, No. 1/1980, pp. 3-44.

${ }^{28}$ GÓMEZ-REINO, M., "Las elecciones europeas de 2009 y el espectro de la extrema derecha", ARI 101/2009, Real Instituto Elcano, Madrid, pp. 2-3. Ello ha sido confirmado en las elecciones al PE que se realizan desde 1979. JUDGE, D. y EARNSHAW, D., op. cit., nota 5 , p. 71.

29 USHERWOOD, S. y STARTIN, N., op. cit., nota 10, p. 4

${ }^{30}$ BRACK, N., op. cit., nota 6, p. 87. 
de centro (Socialistas, Cristiano-demócratas y Liberales) a ser favorables a una mayor unidad europea. ${ }^{31}$ Esta tendencia «pro-integración» que el PE ha asumido tradicionalmente no ha impedido, entonces, desde las primeras elecciones directas, y, en especial desde 1994, la actuación de fuerzas críticas u opositoras a la integración europea, a través de diputados euroescépticos. Con los años, éstos han visto acrecentado su número, aunque haya variado su organización interna.

Luego de las elecciones de 1994, los diputados euroescépticos se organizaron en diferentes grupos: el Grupo de Alianza Democrática Europea (ADE) (integrado por gaullistas franceses, el Fianna Fail (FF) irlandés, y diputados conservadores griegos y portugueses) $;{ }^{32}$ el Grupo Europa de las Naciones (EDN), ${ }^{33}$ con partidos nacionalistas franceses y daneses contrarios al Tratado de Maastricht, y la derecha confesional holandesa; y Forza Europa (FE), compuesto por los veintisiete diputados de Forza Italia (FI). Además, había partidos euroescépticos en el Grupo Confederal de la Izquierda Unitaria Europea (Gauche Unitaire Européenne, GUE), donde estaban los comunistas franceses, griegos y portugueses. Dicho grupo modificó su nombre y pasó a llamarse GUE/NGL (al agregar la sigla NGL del inglés Nordic Green Left ${ }^{34}$ para incluir a la Izquierda Verde Nórdica, al incorporar a suecos y finlandeses en 1995. Los partidos regionalistas de centro-izquierda y otros nacionalistas estuvieron agrupados en la Cuarta Legislatura en la Alianza Radical Europea (ARE) ${ }^{35}$ que se unieron con partidos ecologistas para formar el Grupo de los Verdes/Alianza Libre Europea (V/ ALE) a partir de 1999.

En la Quinta Legislatura (1999-2004), los dos principales grupos euroescépticos aparecidos en 1994 se mantuvieron, con algunos cambios en su composición: el grupo EDN/I-EDN se convirtió en el Grupo de la Europa de las Democracias y Diferencias (EDD), formado con algunos remanentes del I-EDN: partidos radicales de derecha franceses y holandeses,

31 SCULLY, R., "Between Nation, Party and Identity: a Study of European Parliamentarians", EPRG Working Paper, No. 5/1999, p. 9.

32 En julio de 1995 FE se incorporó al grupo ADE, que pasó a llamarse Unión por Europa (UPE).

${ }^{33}$ En la Cuarta Legislatura sufrió un cambio de denominación al pasar a llamarse Grupo de Independientes por una Europa de las Naciones (I-EDN) el 20 de diciembre de 1996.

34 En el PE este grupo es conocido por las siglas GUE/NGL y no por sus siglas en otros idiomas, y por ello es la sigla que utilizamos en este trabajo.

35 La ARE incluía en 1994 a radicales franceses e italianos, nacionalistas escoceses, flamencos y un canario (que fue sustituido por un valenciano y éste por un aragonés). En enero de 1999 alcanzó los veintiún miembros al incorporar un eurodiputado de Coalición Galega y un ecologista de Luxemburgo, pero dejó de existir en junio de 1999. CORBETT, R.; JACOBS, F. y SHACKLETON, M., The European Parliament, John Harper Publishing, Londres, 2011 (1990), p. 84. 
y partidos anti-UE, uno británico (Partido de la Independencia del Reino Unido, United Kingdom Independence Party, UKIP) y otro danés (Folkebevagelsen mod EU, FmEU); y la ADE/UPE se convirtió en el Grupo Unión por la Europa de las Naciones (UEN), una alianza entre euroescépticos y nacionalistas compuesta por partidos conservadores irlandeses y portugueses, post-fascistas italianos, Partido del Pueblo danés (Dansk Folkeparti, DF) y euroescépticos de derecha franceses. También en la Quinta Legislatura encontramos al GUE/NGL como otro terreno fértil para euroescépticos en el PE, con euroescépticos daneses, comunistas y socialistas radicales franceses, el Partido del Socialismo Demócrata alemán (Partei des Demokratischen Sozialismus, PDS), comunistas griegos, portugueses, españoles e italianos, socialistas holandeses e izquierda finlandesa y sueca. Adicionalmente, hallamos euroescépticos entre los Verdes y los 'no inscritos'.

En la Sexta Legislatura (2004-2009), los euroescépticos representaron alrededor del $23 \%$ de la Eurocámara (tabla n. ${ }^{\circ} 1$ ), organizados en el grupo UEN de partidos euroescépticos 'blandos', los partidos anti-UE del Grupo Independencia/Democracia (IND/DEM), el grupo de comunistas y de la extrema izquierda GUE/NGL y los 'no inscritos', ${ }^{36}$ así como el subgrupo 'DE', liderado por los Conservadores británicos, dentro del grupo Partido Popular Europeo-Demócratas Europeos (PPE-DE). La novedad de dicha legislatura fue la aparición en escena de partidos euroescépticos de los nuevos Estados miembros, como por ejemplo, el Partido Democrático Cívico (Občanská demokratická strana, ODS) checo, o la Alianza de Jóvenes Demócratas (Fiatal Demokraták Szövetsége, Fidesz) húngaro.

En efecto, con el ingreso de los diputados de los nuevos Estados miembros, al grupo nacionalista UEN se incorporó el Movimiento 'Ley y Justicia' polaco (Prawo i Sprawiedliwość, PiS), los partidos populares agrarios de los tres países bálticos y ultraconservadores lituanos, la Liga Norte (Lega Nord, LN) italiana y otros tres partidos polacos agrarios y conservadores. Por su parte, el EDD se convirtió en el Grupo IND/DEM, como mencionamos, con el UKIP británico, Liga de las Familias polacas (Liga Polskich Rodzin, LPR), y euroescépticos suecos, franceses, daneses y derecha confesional holandesa, entre otros; mientras que el grupo de comunistas y de la extrema izquierda (GUE/NGL) sumó a comunistas checos, chipriotas y eslovacos, y también al Bloco de Esquerda portugués, Sinn Féin irlandés y Movimiento anti-UE danés.

Al analizar la composición de la Séptima Legislatura del PE (20092014), y en comparación con las tres legislaturas anteriores, el número de diputados euroescépticos no necesariamente aumentó, aunque estaban agru-

36 LECONTE, C. op. cit., nota 2, p. 130. 
pados en distintas constelaciones, dado que algunos grupos pre-existentes no lograron re-editarse en 2009, mientras que nuevos grupos fueron creados. La representación de las fuerzas euroescépticas en la Séptima Legislatura rondaba el $22 \%$ de la asamblea, una cifra análoga a periodos anteriores (tabla $n .{ }^{\circ} 1$ ) ${ }^{37}$ y relativamente «inocua» en términos de influencia en el PE, ya que estos diputados no lograron conformarse en un único «bloque» que incluyese a euroescépticos 'blandos' y 'duros'.

En dicho periodo legislativo, los partidos euroescépticos quedaron organizados en dos agrupaciones: el Grupo Conservadores y Reformistas Europeos (European Conservatives and Reformists, ECR) y el Grupo Europa de la Libertad y la Democracia (Europe of Freedom and Democracy, EFD). ${ }^{38}$ El grupo ECR, de euroescépticos 'blandos', ${ }^{39}$ estaba liderado por los Conservadores británicos, junto con el ODS checo, y partidos nacionalistas polacos. Ese grupo se basaba en los valores conservadores y una creencia compartida en una Europa no federal..$^{40}$ Por su parte, los euroescépticos 'duros' se organizaron en el grupo EFD, con remanentes de dos grupos que existían en la legislatura anterior. En el EFD se hallaban el UKIP británico, la LN italiana, la Concentración Popular Ortodoxa (Laïkós Orthódoxos Synagermós, LAOS) griega, un partido liberal lituano, y un partido católico nacionalista polaco. ${ }^{41}$ Finalmente, el núcleo duro de la derecha radical ${ }^{42}$ no consiguió formar su propio grupo parlamentario y sus diputados quedaron registrados como 'no inscritos'. ${ }^{43}$

La división de grupos políticos en la Séptima Legislatura materializaba el abierto euroescepticismo de los Conservadores británicos al romper con el PPE de centro-derecha y conformar un grupo propio, aunque la tendencia anti-integración de los Tories ya era manifiesta por lo menos desde 1999. Los euroescépticos 'duros' - que representaban las verdaderas fuerzas opositoras y obstruccionistas en el PE - fueron minoritarios y estuvieron atomizados entre el EFD y los 'no inscritos', sin influencia real.

Las últimas elecciones de diputados al PE se celebraron del 22 al 25 de mayo de 2014 en los veintiocho Estados miembros de la UE. Con una parti-

37 ÁLVAREZ, M.V., "El euroescepticismo en una Unión Europea en crisis: ¿viejo fenómeno en nuevas odres?”, Revista Integración y Cooperación Internacional, No. 13/2012, pp. 13-14.

38 También había partidos euroescépticos entre los Verdes (V/ALE) y en el grupo GUE/ NGL.

39 USHERWOOD, S. y STARTIN, N., op. cit., nota 10, p. 7.

40 Ibid, p. 13.

41 Incluía otros siete partidos de diferentes países, con un diputado cada uno.

42 Incluyendo Front National (FN) francés, Freiheitliche Partei Österreichs (FPÖ) austríaco, Vlaams Belang belga, los búlgaros de Ataka y los rumanos de Partidul Rômania Mare.

43 ÁLVAREZ, M.V., op. cit., nota 35, p. 13. 
cipación promedio en toda la UE del 42,54\%, ${ }^{44}$ unas décimas por debajo de la ya baja participación de los comicios de 2009 (que había sido del 43\%), los votantes europeos se inclinaron por fuerzas políticas alternativas, en su mayoría euroescépticas. En efecto, un importante caudal de votos sobrevino para partidos de protesta anti-europeos y anti-inmigración, replicando la naturaleza de las elecciones europeas como «elecciones nacionales de segundo orden», como hemos comentado.

De esta manera, en el actual periodo legislativo, el porcentaje de euroescépticos se incrementó de manera notable, especialmente por el aumento del número de diputados de dos grupos euroescépticos: el Grupo de la Europa de la Libertad y la Democracia Directa (EFDD) ${ }^{45}$ y el ECR (tabla n. ${ }^{\circ}$ 1). Sin embargo, el principal temor, que era la conformación de un grupo político euroescéptico 'duro' de extrema derecha, no se vio concretado.

Recordemos que los grupos políticos en el PE nacen, se unen, se separan o cesan de existir, pero además, los diputados (en ocasiones, individualmente y en otras, en bloque) también cambian de afiliación y pasan de un grupo a otro. ${ }^{46}$ Este tipo de mutación partidaria ('party-switching') a menudo está motivado por factores internos a los propios grupos en el PE. En otros casos, se deben a desavenencias a nivel doméstico: las diferencias que tienen en el escenario nacional se trasladan al PE. ${ }^{47}$ Las cuatro legislaturas estudiadas se caracterizan por la fluidez de la composición de los grupos parlamentarios. Coincidiendo con Evans y Vink, consideramos que «party group switching may be seen more as a natural element, than as an aberration of the political system of the EP».48

Para los diputados y partidos euroescépticos, el fenómeno también se sostiene en el tiempo: los diputados euroescépticos cambiaron de grupo de una legislatura a otra y aún dentro de una misma legislatura. Las desercio-

${ }^{44}$ Inicialmente los datos provisorios indicaban un leve aumento de la participación con el 43,09\%, pero posteriormente las cifras definitivas constataron la tendencia a la baja. Parlamento Europeo, Resultados de las elecciones 2014, http://www.resultados-elecciones2014.eu/ es/turnout.html (última consulta: 14/08/2014).

45 EL EFDD fue disuelto el 16 de octubre de 2014 al no cumplir con los requisitos para la formación de un grupo político por la renuncia de una eurodiputada letona. El 20 de octubre el grupo volvió a formarse gracias a la entrada de un eurodiputado polaco de extrema derecha. FARIZA, I. "Los eurófobos reconstruyen su grupo en el Parlamento Europeo", Elpais.com, 21.10.2014, http://internacional.elpais.com/internacional/2014/10/20/ actualidad/1413820636_708250.html (última consulta: 22/10/2014)

46 McELROY, G. y BENOIT, K., "Policy positioning in the European Parliament", European Union Politics, Vol. 13 No. 1/2011, p. 151

${ }^{47}$ Ibid., p. 152.

48 EVANS, A. M. y VINK, M. P., "Measuring group switching in the European Parliament: Methodology, data and trends (1979-2009)", Análise Social, Vol. XLVII (1. $\left.{ }^{\circ}\right)$, No. 202/2012, p. 110. 
Tabla n. ${ }^{0} 1$

Grupos euroescépticos de la Cuarta a la Octava legislaturas del PE (1994-2014)

\begin{tabular}{|c|c|c|c|c|c|c|c|c|c|c|c|c|c|c|}
\hline & $\begin{array}{c}\text { Cuarta } \\
\text { Legislatura }\end{array}$ & Inicio & Fin & $\begin{array}{c}\text { Quinta } \\
\text { Legislatura }\end{array}$ & Inicio & Fin & $\begin{array}{c}\text { Sexta } \\
\text { Legislatura }\end{array}$ & Inicio & Fin & $\begin{array}{c}\text { Séptima } \\
\text { Legislatura }\end{array}$ & Inicio & Fin $\dagger$ & $\begin{array}{c}\text { Octava } \\
\text { Legislatura }\end{array}$ & $\begin{array}{c}\text { Inicio } \\
\alpha\end{array}$ \\
\hline \multirow{7}{*}{ Grupos } & GUE & 28 & 34 & GUE/NGL & 42 & 55 & GUE/NGL & 41 & 41 & GUE/NGL & 35 & 34 & GUE/NGL & 37 \\
\hline & EDN & 19 & 15 & UEN & 30 & 30 & UEN & 27 & 44 & & & & & \\
\hline & $\mathrm{FE}$ & 27 & $34 *$ & EDD & 16 & 18 & $\begin{array}{l}\text { I N D / D E M } \\
\text { (ex EDD) }\end{array}$ & 37 & 22 & EFD & 32 & 32 & EFDD & 48 \\
\hline & ADE o RDE & 26 & & & & & & & & & & & & \\
\hline & & & & $\begin{array}{l}\text { Subgrupo DE } \\
\text { (PPE-DE) }\end{array}$ & 37 & 38 & $\begin{array}{l}\text { Subgrupo DE } \\
\text { (PPE-DE) }\end{array}$ & 40 & 39 & ECR & 54 & 56 & ECR & 70 \\
\hline & Verdes & 8 & 8 & V/ALE & 11 & 11 & V/ALE & 9 & 9 & V/ALE & 13 & 13 & V/ALE & 18 \\
\hline & NI & 27 & 38 & NI & 9 & 37 & NI & 29 & 30 & NI & 27 & 28 & NI & 52 \\
\hline Total e. & & 135 & 129 & & 145 & 189 & & 183 & 185 & & 161 & 163 & & 225 \\
\hline Total d. & & 567 & 626 & & 626 & $788^{\circ}$ & & 732 & $785^{\circ}$ & & 736 & $766^{\dagger}$ & & $751^{\alpha}$ \\
\hline$\%$ / total & & 23,8 & 20,6 & & 23,1 & 23,9 & & 25,0 & 23,5 & & 21,8 & 21,3 & & 29,9 \\
\hline
\end{tabular}

Fuente: Elaboración propia en base a la página web del Parlamento Europeo.

Nota: Sólo se contabilizaron diputados de partidos euroescépticos, y no la totalidad de los diputados de los grupos políticos mencionados. Dada la volatilidad en la composición de los grupos, debemos advertir que esta tabla puede contener variaciones respecto a cálculos de otras fuentes.

* Forza Italia (FI) en 1994 quedó registrado como Forza Europa, y en julio de 1995, se incorporó al grupo ADE. En mayo de 1999 FI se integró al grupo PPE-DE.

- Número transitorio de diputados para incorporar diputados de nuevos Estados miembros.

† Desde la entrada de Croacia a la UE el 1. ${ }^{\circ}$ de julio de 2013, el PE estuvo compuesto por 766 diputados.

a Según composición al 01/07/2014. El PE en la Octava Legislatura está conformado por 751 diputados. 
nes de los diputados euroescépticos han sido más numerosas que aquéllas que afectaron a los grupos mayoritarios. ${ }^{49}$ Las razones son variadas, pero para los euroescépticos, el hecho de tener un escaño en una institución europea cuya existencia desprecian y cuya legitimidad cuestionan, puede resultar en una situación poco cómoda a la hora de elegir compañeros de grupo.

En este trabajo apuntamos a conocer el comportamiento de votación de los diputados euroescépticos en forma general a lo largo del periodo de estudio - analizado a través del índice de cohesión en votaciones nominales en forma general,$- y$, asimismo, a distinguir cómo votan cuando tienen que decidir si respaldan, por ejemplo, la promoción de una mayor integración europea, el apoyo a reformas de los Tratados, o el ingreso de nuevos Estados miembros. Logramos este tipo de análisis gracias al estudio del comportamiento legislativo según las temáticas abordadas en las votaciones. Finalmente, examinamos el comportamiento político, a través de diversas acciones y estrategias que los diputados tienen a su disposición en forma individual, diferentes a votar.

\section{El comportamiento legislativo general de los diputados euroescépticos de la Cuarta a la Séptima legislaturas}

Al igual que la abundante literatura especializada sobre comportamiento legislativo en el $\mathrm{PE},{ }^{50}$ analizamos la cohesión interna de los grupos políticos en el PE. ${ }^{51}$ La cohesión mide el grado en que los miembros de un grupo político votan juntos como un bloque. Cuanto mayor sea el índice, más cohesivo es un grupo..$^{52}$ Sin embargo, nuestro trabajo no se enfocó en averiguar

49 BENEDETTO, G., "Explaining the failure of Euroscepticism in the European Parliament", en SZCZERBIAK, A. y TAGGART P. (eds.), Opposing Europe? The Comparative Party Politics of Euroscepticism, Volume 2 Comparative and Theoretical Perspectives, Oxford University Press, Oxford, 2008, p. 141

50 Vid. HIX, S., "Legislative Behaviour and Party Competition in the European Parliament: An Application of Nominate to the EU", Journal of Common Market Studies, Vol. 39, No. 4/2001, pp. 663-688; NOURY, A., "Ideology, Nationality, and Euro-Parliamentarians", European Union Politics, No. 3/2002, pp. 33-58.; HIX, S., NOURY, A. y ROLAND, G., op. cit., nota 5; KREPPEL, A., op . cit., nota 5, entre muchos otros.

${ }^{51}$ El corpus de análisis está constituido por la totalidad de las veintidós mil seiscientas cuarenta y cinco votaciones nominales de las cuatro legislaturas. Investigamos el índice de cohesión teniendo en cuenta las votaciones nominales en general y también según la temática de las votaciones.

${ }^{52}$ Las tasas de cohesión se calculan mediante la comparación de las decisiones de voto de los diputados individuales dentro de cada grupo: la escala oscila entre un mínimo de 0 (si un grupo está dividido por la mitad en cada votación) hasta un máximo de 1 (si todos los miembros de un grupo de votan de la misma manera en todos los votos). 
si los eurodiputados votaban más a lo largo de líneas partidarias transnacionales que nacionales ${ }^{53}$ sino que, por el contrario, examinamos una dimensión «secundaria» en el PE, el eje pro/anti-integración.

Diversos estudios han comprobado que en el PE los grupos mayoritarios son más cohesivos que los grupos minoritarios. ${ }^{54} \mathrm{~A}$ mayor tamaño del grupo, mayor influencia en el comportamiento de sus miembros, y por lo tanto, más alto su índice de cohesión. En general, los grupos mayoritarios poseen diferentes (y poderosas) estrategias e instrumentos para «disciplinar» a sus miembros. Correlativamente, los grupos pequeños no se benefician de altos índices de cohesión. A su vez, la falta de cohesión interna conspira contra sus posibilidades de influir en la toma de decisiones en el PE.

Nuestro análisis confirma altos índices de cohesión a lo largo de las cuatro legislaturas para los grupos mayoritarios, con índices similares para los Socialistas europeos y los Liberales, aunque con cierta tendencia descendente para el PPE-DE, probablemente por el incremento del euroescepticismo de los Conservadores británicos - que se hizo patente con la creación de la sub-sección 'Demócratas Europeos' en 1999- quienes votaron en contra del grupo en numerosas ocasiones..$^{55}$ De la misma manera, el retorno del PPE a altos índices en la Séptima Legislatura podría explicarse parcialmente, entre otras razones, por el alejamiento de los Conservadores británicos del grupo en ese periodo. Mientras, y de manera importante para nuestro trabajo, la cohesión de votación de los grupos políticos minoritarios se mantuvo en bajos niveles, y tendió a disminuir a lo largo de todo el periodo.

Resulta interesante destacar que el grupo V/V-ALE fue el grupo con los valores más altos en los cuatro periodos legislativos, y fue, inclusive, más cohesivo que los Socialistas y el PPE. Mientras, el grupo con menores índices de cohesión resultó ser el grupo de partidos euroescépticos 'duros' EDN/EDD/IND-DEM/EFD. Además, su índice fue decreciendo de manera visible en cada periodo (Gráfico n. ${ }^{\circ}$ 1). En las cuatro legislaturas, los euroescépticos 'duros', indicados como las «fuerzas de protesta» al interior del PE, ${ }^{56}$ presentaron bajos niveles de consenso al votar.

${ }^{53}$ El PE posee un sistema de partidos que requiere que los grupos políticos sean cohesivos, es decir, que voten conjuntamente en las diferentes votaciones, para tener alguna influencia en el resultado final. HIX, S., NOURY, A. y ROLAND, G., op. cit., nota 5, p. 87.

${ }^{54}$ Ibid, pp. 97, 101.

55 Vid. LECONTE, C., op. cit., nota 2, p. 132; HIX, S., op. cit., 2001, nota 48, p. 684; BENEDETTO, G., op. cit., nota 47, p. 130.

56 Vid. HIX, S. NOURY, A. y ROLAND, G., op. cit., nota 5, p. 150. 


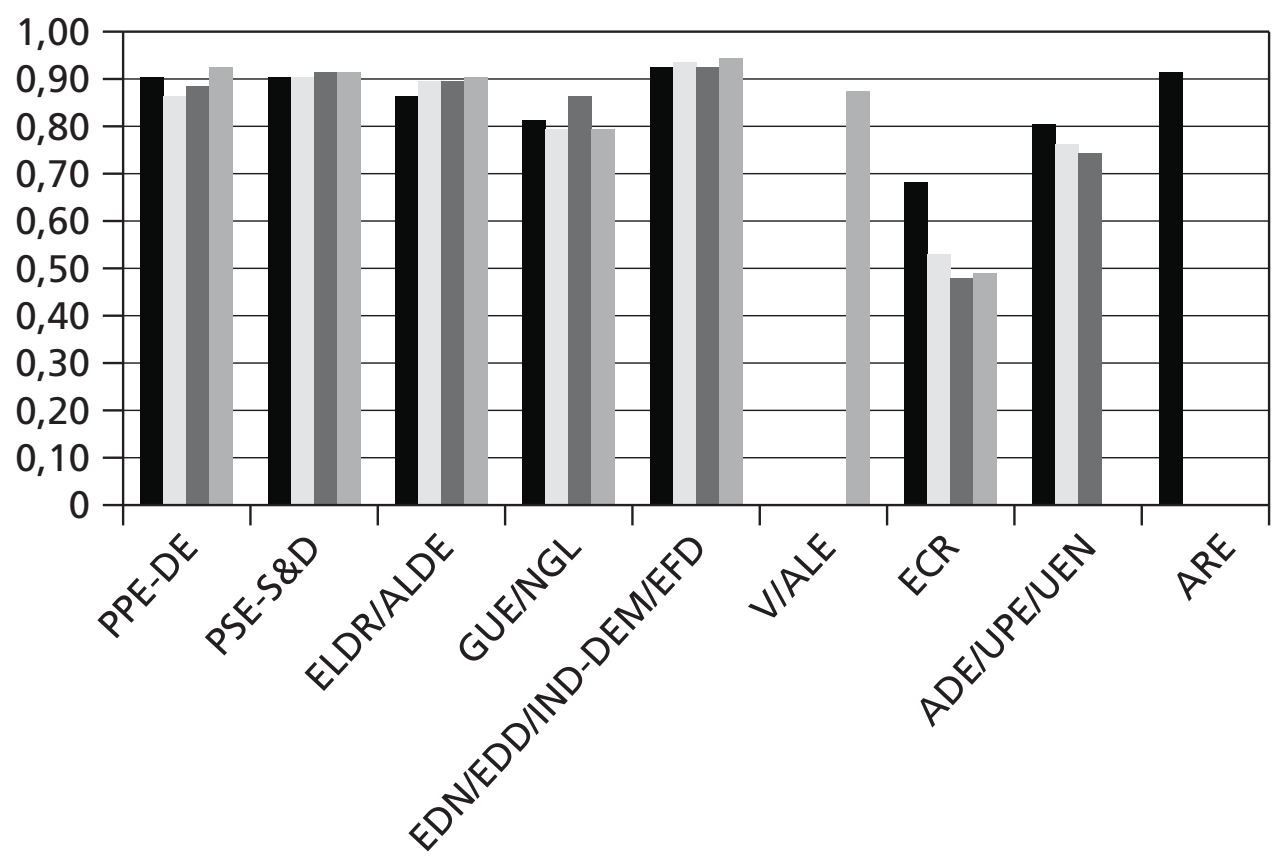

PE4

PE5

PE6

PE7

Fuente: Elaboración propia en base a HIX, S. y NOURY, A. «After Enlargement: Voting Patterns in the Sixth European Parliament», Legislative Studies Quarterly, Vol. 34, No. 2/2009, pp. 159-174, y datos de Votewatch.eu

\section{Gráfico n. ${ }^{\circ} 1$}

Índices de cohesión por grupo político en la Cuarta, Quinta, Sexta y Séptima legislaturas (1994-2014)

La baja cohesión del grupo EDN/EDD/IND-DEM/EFD no es sorprendente si tenemos en cuenta la diversidad partidaria y la heterogeneidad ideológica de esta formación. ${ }^{57}$ Los diputados de partidos euroescépticos 'duros', extendidos desde la extrema izquierda a la extrema derecha, votaron menos cohesivamente que aquéllos de partidos euroescépticos 'blandos', como los del grupo ADE/UPE/UEN o del GUE/NGL.

Adicionalmente, cuando un grupo es pequeño resulta más difícil influir en la toma de decisiones del PE y en el establecimiento de su agenda. Esto le da pocas razones a sus líderes para disciplinar a sus miembros y su voto, ya que hay poco en juego. ${ }^{58}$ Un factor suplementario que puede explicar la baja cohesión de los grupos con diputados euroescépticos, como el EDN/ EDD/IND-DEM, es que gozan de libertad a la hora de votar, y por lo tanto,

${ }^{57}$ La heterogeneidad ideológica fue clara en el grupo EDD y el grupo IND/DEM, que incluían partidos euroescépticos de izquierda y de derecha. El grupo EFD tenía una orientación más clara hacia la derecha. CORBETT, R. et. al, op . cit., nota 33, p. 107. Sin embargo, no por ello su cohesión interna aumentó.

58 MORRIS, M., op. cit., nota 4, p. 35 
si no se les exige disciplina de grupo, difícilmente consigan altos niveles de cohesión.

Pese al incremento del número de diputados y de partidos políticos a lo largo de los veinte años bajo estudio, y a la fluidez en la composición de los grupos políticos entre legislaturas o aún dentro de una misma legislatura, los diputados euroescépticos mostraron de forma consistente menores índices de cohesión que los diputados de partidos pro-integración. Como resultado, las fuerzas euroescépticas tuvieron poco impacto práctico en la agenda del PE y en su récord legislativo. ${ }^{59}$

\section{El comportamiento legislativo por tema de los diputados euroescépticos de la Cuarta a la Séptima legislaturas}

Además del estudio del comportamiento de votación en general, en este trabajo investigamos el comportamiento legislativo a través del índice de cohesión en votaciones nominales clasificadas según su temática ${ }^{60}$ Debemos tener presente que el PE no es una asamblea donde se debatan frecuentemente los grandes temas «constitucionales» de la UE. En efecto, el PE posee escasas oportunidades para expedirse sobre los denominados temas «constitucionales» ${ }^{61}$, como el ingreso de nuevos Estados miembros, la profundización del proceso de integración, o las reformas de los Tratados constitutivos.

59 LECONTE, C., op. cit., nota 2, p. 131

${ }^{60}$ La clasificación para la Cuarta, Quinta y Sexta legislaturas diferencia entre las siguientes áreas de políticas: Acuerdo/Espacio Schengen, Agricultura, Ampliación, Asuntos económicos, Asuntos exteriores, Asuntos jurídicos, Asuntos internos del PE, Asuntos monetarios, Ciudadanía europea, Comercio exterior, Derechos Humanos, Educación/Cultura, Empleo/ Asuntos sociales, Espacio de Libertad, Seguridad y Justicia (ELSJ), Justicia/Asuntos de Interior, Igualdad de Género, Inmigración/Asilo, Integración europea, Industria, Energía e Investigación, Inter-institucional, Medio Ambiente/Salud pública, Mercado interior/Protección del Consumidor, PESC, Pesca, Política Regional, Política de Competencia, Política de Desarrollo, Presupuesto, Seguridad/Defensa, Transporte/Turismo y Tratados/Reformas. En la Séptima Legislatura la clasificación incluía las siguientes áreas: Agricultura, Asuntos económicos y monetarios, Asuntos exteriores y Seguridad, Asuntos inter-institucionales y constitucionales, Asuntos internos del PE, Asuntos jurídicos, Asuntos monetarios, Control presupuestario, Comercio exterior, Educación/Cultura, Empleo/Asuntos sociales, Justicia/Asuntos de Interior, Igualdad de Género, Industria, Energía e Investigación, Libertades civiles, Medio Ambiente/Salud pública, Mercado interior/Protección del Consumidor, Peticiones, Pesca, Política Regional, Política de Desarrollo, Presupuesto, Transporte/Turismo.

${ }^{61}$ SCHMITT, H., "The Nature of European Issues: Conceptual Clarifications and Some Empirical Evidence", en DE VREESE, C., SCHMITT, H. (eds.), A European Public Sphere: How much of it do we have and how much do we need?, Mannheim, 2007, p. 13. 
Entre 1994 y 2009, el grupo EDN/EDD/IND-DEM, dentro de bajos niveles generales de cohesión e importantes variaciones de una legislatura a otra, tendió a exhibir mayor coherencia al votar cuestiones como Presupuesto y Asuntos inter-institucionales. El disenso para este grupo político, en esas tres legislaturas, se concentró en temas como la Política de Desarrollo, Igualdad de Género, o Educación y Cultura. Esto es, los factores que mantuvieron al grupo unido fueron sus actitudes euroescépticas y los beneficios materiales de conformar un grupo político dentro del PE. ${ }^{62}$ En la Séptima Legislatura, su sucesor, el EFD, también dentro de una exigua cohesión, fue proclive a votar de manera consensuada en Control presupuestario, Presupuesto, Industria, Asuntos inter-institucionales y Justicia/Asuntos de Interior, ${ }^{63}$ mientras que tendió a mostrar disenso al votar sobre Educación y Cultura, Mercado interno/Protección al consumidor, y temas sociales.

Por su parte, el grupo ADE/UPE/UEN, existente entre 1994 y 2009, votó de manera disciplinada en Política de Competencia y Política de Desarrollo en la Cuarta Legislatura, y lo hizo así para los temas agrícolas, pesqueros, y la Política Regional en la Quinta. En la Sexta Legislatura, coincidió más a la hora de votar en temas de Política de Desarrollo y Comercio Exterior. A lo largo de las tres legislaturas en las cuales existió, este grupo fue poco cohesivo al votar en temas «centrales» a su agenda pro-soberanía.$^{64}$ La supuesta «compatibilidad» de los partidos que lo conformaban se manifestó en pocas ocasiones. En especial, la diversidad de puntos de vista de los euroescépticos 'blandos' y nacionalistas pro-europeos al interior del grupo les impidió ser coherentes en los temas vinculados a «más» $\mathrm{o}$ «menos» Europa.

El Grupo GUE/GUE-NGL, por otro lado, exhibió los mayores índices de cohesión en cuestiones prioritarias de su agenda programática, como la Política de Desarrollo, Igualdad de Género, Asuntos sociales, y Comercio Exterior. Este grupo, conformado por partidos comunistas, ex comunistas, y socialistas, consensuaba al votar en cuestiones que atravesaban el eje izquierda-derecha, mientras que reflejaba sus diferencias internas en cuestiones «constitucionales». En estos temas, los partidos que lo integraban conservaban su propia identidad y posturas.

62 BENEDETTO, G., op. cit., nota 47, p. 141

63 También tuvieron altos niveles de cohesión en Asuntos internos del PE pero incluía solo ocho votaciones.

${ }^{64}$ STARTIN, N., "Where to for the Radical Right in the European Parliament? The Rise and Fall of Transnational Political Cooperation", Perspectives on European Politics and Society, Vol. 11 No. 4/2010, p. 445. 
Los diputados del Grupo V/V-ALE, dentro de una generalizada alta cohesión, ostentaron mayor consenso al votar temas prioritarios en su plataforma, como Medio Ambiente y Salud Pública, Política de Desarrollo, Mercado interno/Protección del Consumidor, y Comercio Exterior. Los Verdes afirmaban esforzarse para que Europa fuese líder mundial en términos de protección del medio ambiente, la paz y la justicia social, una globalización justa y en la defensa por los derechos humanos. El disenso surgió en temas vinculados a la profundización de la integración, como Asuntos Económicos y Monetarios, y Asuntos Exteriores y Seguridad.

Por su parte, el grupo ECR, que surgió en 2009 de una escisión del grupo mayoritario PPE-DE, tendió a votar más homogéneamente en Asuntos Inter-institucionales, Asuntos Exteriores y Seguridad, y Comercio Exterior, mientras que encontró dificultades para consensuar en Política Regional, Agricultura y Política de Desarrollo. De esta manera, esta «mezcla» poco coherente ${ }^{65}$ de partidos conservadores liberales ${ }^{66}$ y conservadores nacionalistas,${ }^{67}$ con índices más bajos de cohesión que los grupos mayoritarios, logró consensuar en temas relevantes de la agenda euroescéptica de los Conservadores británicos. ${ }^{68}$

En síntesis, mientras los euroescépticos 'duros', oponentes tenaces a la integración europea, aunque con variaciones a lo largo del periodo bajo estudio, fueron proclives a actuar de forma relativamente homogénea cuando se trató de demostrar en las votaciones su oposición a la UE, los diputados euroescépticos 'blandos' no lo consiguieron. El euroescepticismo 'blando', prescindiendo de una oposición frontal y abierta a la UE, y nutriéndose de una enorme variedad de actitudes críticas sobre diversos procesos, instituciones y políticas de la UE, se manifestó en tendencias de comportamiento de votación disímiles entre sus representantes en el PE.

65 BALE, T., HANLEY, S. y SZCZERBIAK, A., «'May Contain Nuts'? The Reality behind the Rhetoric Surrounding the British Conservatives' New Group in the European Parliament», The Political Quarterly, Vol. 81, No. 1/2010, p. 97.

${ }^{66}$ Conservadores británicos, ODS, Lijst Dedecker (LDD) belga y Magyar Demokrata Fórum (MDF) húngaro.

67 PiS polaco y Tevzemei un Brivibai/LNNK (TB-LNNK) letón.

68 Ya en su manifiesto de 1999 los Conservadores defendían la cooperación intergubernamental, en particular en defensa y política exterior y asuntos de Justicia e Interior. También era importante para ellos limitar el significado político de las instituciones comunitarias. GAGATEK, W., «British Conservative Party and the Group of the European People's Party - European Democrats in the European Parliament - an analysis of the history and present shape of difficult relationships», Międzynarodowy Przeglqd Polityczny (6)/2004, p. 171. 


\section{El comportamiento político de los diputados euroescépticos de la Cuarta a la Séptima legislaturas}

El concepto de comportamiento político fue incluido para destacar que los diputados euroescépticos -y también los eurodiputados en generalrealizan otras muchas acciones dentro del PE además de votar en sesión plenaria. Exponemos a continuación la evidencia encontrada a lo largo de las cuatro legislaturas respecto de la asistencia de los diputados a las votaciones, la elaboración de informes en comisión, la formulación de preguntas parlamentarias escritas, la redacción de propuestas de resolución, y la realización de intervenciones en el Pleno.

La baja asistencia al Pleno resultó ser un rasgo del comportamiento político de los diputados euroescépticos, al caracterizarse por su esporádica asiduidad vis-à-vis sus colegas pro-integración. ${ }^{69}$ Esto puede ser interpretado tanto como una estrategia motivada por una falta de interés en el mandato como por un rechazo absoluto a participar de las actividades diarias de la institución..$^{70}$ Consistentemente, los tres grupos con mayores índices de asistencia fueron grupos mayoritarios: el PPE, los Socialistas y los Verdes. Excepto en la Sexta Legislatura ${ }^{71}$ los diputados que menos asistieron fueron los 'no inscritos'. Con oscilaciones a lo largo de las legislaturas, tanto los euroescépticos 'duros' del grupo EDN/EDD/IND-DEM/EFD como los euroescépticos 'blandos' del ADE/UPE/UEN y el GUE/NGL participaron del Pleno en menor proporción que los diputados de grupos mayoritarios. ${ }^{72}$ En general, al no participar tan activamente en las votaciones, los diputados euroescépticos perdieron la oportunidad de ejercer mayor influencia en la toma de decisiones en el PE.

La labor en comisiones parlamentarias constituye otra actividad esencial en el PE, especialmente para la tarea legislativa y presupuestaria. En las cuatro legislaturas, fueron los diputados de partidos pro-integración, y en menor medida, los diputados de partidos euroescépticos 'blandos', ${ }^{73}$ quienes tuvieron a su cargo la elaboración de la mayor cantidad de informes de

69 Esto se corroboró en las cuatro legislaturas bajo estudio, aunque de forma más notoria en la Sexta y Séptima legislaturas.

70 BRACK, N., "Eurosceptics in the European Parliament: Exit or Voice?", Journal of European Integration, Vol. 34, No. 2/2012, p. 154.

71 En la Sexta Legislatura el grupo que asistió con menos frecuencia al Pleno fue el IND/ DEM.

72 En el periodo bajo estudio el índice de asistencia promedio en el PE fluctuó entre el $68 \%$ y $85 \%$ de los diputados, aunque verificamos una tendencia al aumento de la participación de los diputados en el tiempo.

73 Con la excepción de los diputados del GUE/NGL, que quedaron por debajo del promedio general de rapports en las cuatro legislaturas. 
comisiones parlamentarias. Quedaron excluidos de este tipo de actividad los diputados de partidos euroescépticos 'duros' ${ }^{74}$

La escasez de informes presentados por diputados de partidos euroescépticos 'duros' - especialmente aquellos de extrema derecha- resultó de una combinación de la actitud del resto de los diputados, que imponían a sus colegas una especie de «cordon sannitaire» ${ }^{75}$ así como también, debemos resaltarlo, de una libre elección de los diputados euroescépticos más radicales, quienes prefirieron la «auto-exclusión» y mantenerse al margen de actividades vinculadas a las funciones legislativas del PE, lo cual implicaba tejer alianzas y compromisos con diputados no euroescépticos. ${ }^{76}$

Las preguntas parlamentarias, a su vez, constituyen una herramienta relevante para obtener información o una explicación sobre un asunto determinado que afecta a la competencia del PE o en relación con las actividades de la UE en su conjunto. ${ }^{77}$ Los eurodiputados formularon un número creciente de preguntas escritas en cada legislatura, congruentemente con el aumento gradual de sus competencias en materia de control del «ejecutivo» de la UE en cada reforma de los Tratados. ${ }^{78}$

En cuanto a la cantidad de preguntas escritas formulada por los diputados euroescépticos, éstos estuvieron por encima del promedio general del $\mathrm{PE}$ en las cuatro legislaturas, especialmente los diputados del GUE/NGL. En las Cuarta y Quinta legislaturas se destacaron también los diputados euroescépticos 'blandos' de V/V-ALE, mientras que en la Sexta y Séptimas notamos un aumento de la frecuencia de uso de esta herramienta por parte de los euroescépticos 'duros' de EDN/EDD/IND-DEM/EFD. ${ }^{79}$

${ }^{74}$ Por cada propuesta o iniciativa legislativa, los grupos políticos que componen el PE designan a un ponente a través de un sistema de licitación en el cual cada grupo político tiene una cantidad de puntos proporcional a la cantidad de escaños.

75 ALMEIDA, D., "Europeanized Eurosceptics? Radical Right Parties and European Integration", Perspectives on European Politics and Society, Vol. 11, No. 3/2010, p. 248.

${ }^{76}$ Ibid, p. 248; BENEDETTO, G., op. cit., nota 47, p. 148

77 El corpus de preguntas parlamentarias utilizado en este trabajo se limitó a las preguntas escritas, que constituyen, la forma de inquirir más popular entre los eurodiputados (RAUNIO, T. 1996, citado por PROKSCH, S. y SLAPIN, J. B., "Parliamentary questions and oversight in the European Union", European Journal of Political Research, Vol. 50, No. 1/2011, p. 8; CORBETT, R. et. al, op. cit., nota 33, p. 317).

${ }_{78}$ El número de preguntas escritas aumentó de aproximadamente 3.300 por año (19901993), a alrededor de 4.000 por año entre 1996 y 2004, antes de dispararse a alrededor de 6.000 preguntas anuales en la Sexta Legislatura (CORBETT, R. et. al, op. cit., nota 33, p. 317).

79 En ese periodo, los diputados de partidos euroescépticos 'duros' formularon un promedio de preguntas parlamentarias que duplicó el promedio del PE, mientras que los diputados de partidos euroescépticos 'blandos' también formularon más preguntas que la media del PE, aunque en menor proporción. 
Estos guarismos revelan que, para los diputados de partidos euroescépticos, las competencias de control resultaron ser un instrumento eficaz a la hora de mostrar su oposición a la UE, formulando una enorme cantidad de preguntas a otras instituciones europeas. Esta tendencia de comportamiento los distinguió de los diputados a favor de la integración, quienes ocuparon menos tiempo en la supervisión y monitoreo de otras instituciones.

Otra de las funciones primordiales de los eurodiputados es la relativa a la competencia deliberativa a través de la elaboración de propuestas de resolución. Nuestro análisis reveló tendencias similares a las encontradas en cuanto a las preguntas parlamentarias: la cantidad media de propuestas de resolución formulada por los diputados de partidos euroescépticos, especialmente de los grupos GUE/NGL, V/V-ALE y ADE/UPE/UEN, fue más elevada que el promedio de propuestas de resolución elaboradas por la totalidad de los eurodiputados en el periodo bajo estudio.

En efecto, el comportamiento pro-activo en la presentación de propuestas de resolución estuvo en manos, particularmente, de los euroescépticos 'blandos', cuyo euroescepticismo moderado los llevó a criticar la UE de una manera constructiva, formulando propuestas de resolución a ser debatidas y tratadas en el recinto. En cambio, el bajo número de propuestas de los euroescépticos 'duros' demostraría que su oposición «de principio» a la UE excluía la posibilidad de presentar otras alternativas al «modelo comunitario». Los euroescépticos 'duros' tampoco aprovecharon las propuestas de resolución como instrumento de comunicación de sus posturas anti-UE, sino que se limitaron a clamar su crítica a la integración a través de intervenciones en sesiones plenarias.

Efectivamente, los diputados de partidos euroescépticos 'duros', especialmente del grupo EDN/EDD/IND-DEM/EFD, ostentaron altos índices de intervenciones en sesión plenaria en las cuatro legislaturas. Los diputados euroescépticos anti-UE adquirieron un alto perfil en los debates legislativos en el Pleno. También se destacaron los diputados euroescépticos 'blandos' del GUE/ NGL y V/V-ALE. Ello es remarcable teniendo en cuenta que los diputados de los grupos mayoritarios son quienes suelen ostentar los cargos internos más importantes - como la Presidencia o las Vicepresidencias del PE - y que, obligatoriamente, deben dirigirse al Pleno para ordenar los debates y las votaciones.

\section{El comportamiento legislativo y político de los diputados euroescépticos en la Octava Legislatura: ¿cambio o continuidad?}

La Octava Legislatura revierte la estabilidad evidenciada en el PE de la proporción de diputados anti-integración, quienes desde 1994 representaban alrededor del $20 \%$ de la asamblea. Actualmente, el porcentaje de euroes- 
cépticos se amplió (tabla n. ${ }^{\circ}$ 1), especialmente por el incremento en el número de diputados de dos grupos euroescépticos: el Grupo EFDD ${ }^{80}$ (que logró volver a conformarse, con las ventajas de financiación, visibilidad e influencia que eso comporta, ganando dieciséis escaños con respecto de 2009), y el ECR (que ganó trece escaños respecto de 2009). Sin embargo, el principal temor, que era la conformación de un grupo político euroescéptico 'duro' de extrema derecha, no se vio concretado ${ }^{81}$ Dada la gran heterogeneidad de los partidos políticos que componen la extrema derecha en el PE, algunos se han incorporado a las coaliciones arriba mencionadas mientras que muchos de ellos quedaron como diputados 'no inscritos', con nula influencia en los asuntos del PE. ${ }^{82}$

Pese al crecimiento en el número de diputados euroescépticos, es probable que se mantenga la dinámica partidaria clásica en el PE, y la conocida «política de compromiso» entre los dos grandes bloques de centro-derecha y centro-izquierda, que conforman la tradicional «grand coalition». Los Socialistas y el PPE dominan la política dentro del PE, pero sin obtener una mayoría absoluta, tal como viene ocurriendo históricamente. ${ }^{83}$ A diferencia, sin embargo, de anteriores legislaturas, cuando los Liberales actuaban manteniendo el equilibrio de poder y como «grupo pivote», ${ }^{84}$ en la Octava Legislatura el tercer puesto corresponde a los euroescépticos (o «eurorealistas») ${ }^{85}$ del ECR. Especialmente en temas anti/pro-integración, será más complejo para Socialistas, e inclusive, para el PPE, tejer consensos y alianzas con el ECR que con los Liberales. Es por ello que para garantizar la gobernabilidad del PE es probable que los grupos principales opten por trabajar más estrechamente que nunca a lo largo de la legislatura. ${ }^{86}$

${ }^{80}$ Conformado por UKIP, junto con M5S y otros partidos menores

81 Si bien en 2013 la líder del FN, Marine Le Pen, y el líder del PVV, Geert Wilders, habían sellado una alianza para crear un nuevo grupo tras las elecciones al PE de 2014, la extrema derecha no pudo conformar un grupo propio. FERRER, I. "La ultraderecha europea sella una alianza". ElPais.com 13.11.2013. http://internacional.elpais.com/internacional/ 2013/11/13/actualidad/1384343925_371743.html (última consulta: 21/12/2013). El PVV vetó finalmente la alianza con el FN por sus tendencias antisemitas. ABELLÁN, L., "Marine Le Pen se queda sin grupo propio en el Parlamento Europeo", ElPais.com 24.06.2014 http:// internacional.elpais.com/internacional/2014/06/24/actualidad/1403635508_955710.html (última consulta: 01/07/2014)

82 Así, especialmente porque los representantes del FN francés forman parte de los 'no inscritos', éstos han obtenido un aumento importante con respecto del período legislativo precedente, agrupando cincuenta y dos bancas.

${ }^{83}$ HIX, S., NOURY, A. y ROLAND, G., op. cit., nota 5, p. 26

${ }^{84}$ CORBETT, R. et. al., op. cit., nota 33, pp. 123-124

85 Ibid, p. 101.

86 LLAUDES, S. "Elecciones al Parlamento Europeo: ¿y ahora qué?”, Comentario Elcano 39/2014, 3/6/2014, p. 2 
Respecto del comportamiento legislativo de los euroescépticos, los primeros meses de funcionamiento del nuevo parlamento ${ }^{87}$ señalan que, como ha ocurrido tradicionalmente, los grupos minoritarios tienden a ser menos cohesivos que los grupos mayoritarios, propensión particularmente puesta de manifiesto en el caso del grupo EFDD. ${ }^{88}$ Por su parte, es posible que los Conservadores británicos y sus aliados, al quedar como tercera fuerza política del PE, deban realizar un importante ejercicio de «gimnasia política» para imponerse como «grupo pivote» entre los Socialistas y el PPE, lo que implicará intentar llevar adelante su agenda «eurorealista» realizando concesiones a los dos grupos mayoritarios pro-integración.

El comportamiento legislativo de los diputados euroescépticos por tema dependerá de las coaliciones internas dentro de los grupos políticos, que han incorporado nuevos partidos nacionales a sus filas. El EFDD, comprometido con la transparencia y la apertura de los procedimientos comunitarios, y contrario a la «centralización» de Bruselas, ${ }^{89}$ probablemente coincida al votar en Control presupuestario, Presupuesto, y Asuntos inter-institucionales. Más aún, la tendencia «anti-globalización» del M-5S italiano podría conducir al consenso interno al votar en Comercio Exterior o Asuntos Exteriores y Seguridad. ${ }^{90}$ Por su parte, los Conservadores británicos y sus socios (especialmente polacos y de otros países de Europa del Este) probablemente tiendan a consensuar en su agenda «anti-federal»: ${ }^{11}$ en Asuntos inter-institucionales, Asuntos Exteriores y de Seguridad, y Comercio Exterior, más que en asuntos de interés nacional como Agricultura, o Política Regional. Los Verdes y el GUE/NGL continuarán priorizando sus respectivos objetivos programáticos.

En cuanto al comportamiento político, los primeros meses de funcionamiento de la actual legislatura muestran, coincidentemente con lo evidenciado en legislaturas anteriores, que los euroescépticos del ECR y EFDD

${ }^{87}$ La sesión inaugural de la Octava Legislatura se celebró el 1. ㅇ de julio de 2014.

88 Datos extraídos de Votewatch.eu sobre "Cohesión de los grupos políticos en todas las áreas de políticas" (01.07.2014-23.10.2014). http://www.votewatch.eu/en/term8-politicalgroup-cohesion.html (última consulta: 24/10/2014)

${ }^{89}$ Carta del Grupo EFDD. http://www.efdgroup.eu/ (última consulta: 01/09/2014)

90 Incluso, dado que en la campaña el M-5S abogó por un plebiscito sobre la pertenencia a la Zona Euro y por la abolición de la normativa de austeridad comunitaria, es probable la coincidencia con el UKIP al votar en el PE sobre Asuntos Económicos y Monetarios. "El Movimiento 5 Estrellas de Grillo se alía con UKIP en el Europarlamento" 13.06.2014 http:// www.publico.es/internacional/527176/el-movimiento-5-estrellas-de-grillo-se-alia-con-ukipen-el-europarlamento (última consulta: 01/09/2014)

91 El grupo se opone al camino hacia un súper Estado europeo federal, remarcando las posibilidades que otorga la cooperación entre Estados más que su integración. Página web del grupo ECR http://ecrgroup.eu/about-us/the-ecr-in-the-european-parliament/ (última consulta: 02/09/2014) 
son los diputados que asisten a las votaciones con menos frecuencia, mientras que los diputados de los grupos mayoritarios son los que más asisten..$^{92}$ Posiblemente los euroescépticos 'duros' del EFDD - y aquéllos entre los 'no inscritos' - queden fuera de la asignación de rapports y dediquen su tiempo a intervenir en el Pleno con discursos «provocadores» como acostumbra el Vice-presidente del EFDD y líder de UKIP, Nigel Farage. Los euroescépticos 'blandos' se dedicarán, con más probabilidad, a redactar propuestas de resolución y realizar preguntas parlamentarias a la Comisión y el Consejo, en su afán por «reformar» la UE y los procesos e instituciones que, según su visión, fallan.

\section{Conclusiones}

El hecho de que los partidos euroescépticos difieran en la intensidad de su oposición a la integración europea y en los argumentos que esgrimen para oponerse a ella, se ve reflejado en diferentes tendencias de conducta entre sus representantes en el PE. La investigación realizada nos ha habilitado para reconocer que esta diversidad de posturas opuestas o críticas respecto del proceso de integración se manifiesta en tendencias disímiles de comportamiento legislativo y político por parte de los diputados euroescépticos en el PE.

Gracias a esta investigación logramos dar cuenta del objetivo general y de los objetivos específicos. En cuanto al primer objetivo específico, referido al comportamiento legislativo de los diputados euroescépticos, escudriñable a través del índice de cohesión en votaciones nominales en general, el análisis demostró que, a pesar de la naturaleza compleja del PE, donde están representados todos los puntos de vista sobre el proyecto integracionista, a lo largo de las cuatro legislaturas existieron amplias mayorías a favor de la integración. Los diputados euroescépticos - tanto 'duros' como 'blandos' - estuvieron divididos en diversos grupos y al interior de dichos grupos, y mostraron bajos niveles de cohesión, en comparación con sus colegas pro-europeos, que se beneficiaron de una fuerte unidad interna en las votaciones. Por lo tanto, con el apoyo de una clara mayoría de sus miembros a favor de una mayor integración, el PE ha sido una institución donde las posturas opuestas a la integración no han podido prevalecer.

Los grupos mayoritarios exhibieron de manera consistente altos índices de cohesión. Paralelamente, los grupos minoritarios presentaron una menor

92 Datos obtenidos de Votewatch.eu. Participación promedio en votaciones nominales (01.07.2014-23.10.2014). http://www.votewatch.eu/en/term8-political-group-participation. html (última consulta: 24/10/2014) 
cohesión interna. Nos parece relevante resaltar que estas tendencias se mantuvieron constantes más allá del incremento del número de diputados y de partidos políticos en el PE a lo largo de los años, y pese a la fluidez en la composición de los grupos políticos - especialmente aquéllos con partidos euroescépticos a su interior - entre legislaturas o aún dentro de una misma legislatura.

Los diputados de partidos euroescépticos 'duros' - en el periodo bajo estudio organizados en el grupo EDN/EDD/IND-DEM/EFD - fueron los diputados menos cohesivos a lo largo de las cuatro legislaturas. Mientras, grupos euroescépticos 'blandos', como el GUE/NGL o ADE/UPE/UEN ostentaron mayor cohesión que los euroescépticos 'duros' pero menor homogeneidad que los diputados pro-integración. El hecho de no encontrarse en los extremos político-ideológicos les permitió a los euroescépticos 'blandos' ciertos niveles de cohesión, aunque la diversidad de su crítica moderada hacia la UE les impidió alcanzar las cotas de consenso de los grupos mayoritarios como los Socialistas, Cristiano-demócratas y Liberales, históricos defensores de una mayor unidad europea.

En definitiva, las fuerzas euroescépticas no lograron ser homogéneas a la hora de votar en la Eurocámara. Su debilidad numérica - en comparación con los grandes grupos tradicionales - , y la fluidez en la composición de los grupos con partidos euroescépticos se complementaron con el reducido tamaño de dichos grupos para dar cuenta de los exiguos niveles de cohesión interna. A su vez, todo ello explica la influencia marginal que los euroescépticos pudieron ejercer en el PE.

El segundo objetivo específico de nuestra investigación proponía examinar las tendencias del comportamiento legislativo de los diputados euroescépticos a través del análisis del índice de cohesión en votaciones nominales clasificadas según temáticas. Pudimos apreciar que diferentes tipos de temáticas generan tendencias diversas de comportamiento por parte de los diputados euroescépticos, contrariamente a la hipótesis nula de que no existe relación entre el contenido de la legislación votada y la forma en que votan los eurodiputados.

La mayor parte de la legislación que trata el PE no se relaciona con la ampliación o la profundización de la UE, ni con reformas institucionales significativas, es decir, no involucra cuestiones «constitucionales». Sin embargo, a través de los dictámenes de conformidad y en consulta, y de sus competencias para deliberar y pronunciarse por propia iniciativa, el PE ha tomado partido sobre dichas cuestiones. Los partidos euroescépticos 'duros', a pesar de ostentar bajos niveles generales de cohesión, fueron proclives a manifestar sus posturas opuestas a la integración europea en sus votaciones. Nos parece interesante señalar que, pese a pertenecer a grupos minoritarios (y a fluctuar de un grupo a otro), a ser diversos ideológica- 
mente, débiles numéricamente, y más aún, pese a contar con amplios márgenes de libertad de acción y votación, los euroescépticos 'duros' tendieron a votar coherentemente en diversos temas del eje pro/anti-integración.

Mientras los oponentes tenaces a la integración europea fueron proclives a actuar de forma relativamente homogénea cuando se trató de demostrar su oposición en votaciones, los diputados euroescépticos 'blandos' no lo lograron. La mayoría de estos diputados tenían puestas sus preferencias en los temas prioritarios de sus agendas programáticas, pero diferían al votar en temas «constitucionales». En términos generales, estaban atomizados en diferentes agrupaciones: el grupo ADE/UPE/UEN - dentro del cual colisionaba el nacionalismo pro-europeo y el euroescepticismo 'blando'-; el grupo GUE/GUE-NGL - concentrado en temas socio-económicos-; y el grupo V/V-ALE - enfocado en llevar adelante la defensa del medio ambiente, la salud pública, y el pacifismo-.

La crítica de los euroescépticos 'blandos' a la integración europea, proponiendo modificaciones a las prácticas y procesos, sin llegar a promover la disolución de la UE ni la retirada de Estados miembros, implicó una oposición mesurada a la integración, aunque no siempre coincidente, en cuanto a los aspectos, políticas, instituciones o procesos objeto de crítica. La amplia diversidad de las posturas críticas sobre la integración europea de los euroescépticos 'blandos' les impidió reflejarlas unánimemente en sus votaciones y por ello, pese a tener niveles generales de cohesión más altos que los euroescépticos 'duros', votaron de forma relativamente heterogénea en diversos temas de la dimensión anti/pro-integración.

Pero en el PE los eurodiputados no solamente votan en sesión plenaria. Nuestra investigación intentó realizar un estudio acabado de la conducta de los diputados euroescépticos, y por ello, el tercer objetivo específico se dirigió a analizar lo que aquí denominamos comportamiento político. Al buscar formas alternativas de conducta en el PE, los diputados euroescépticos hicieron un uso activo de diferentes instrumentos parlamentarios en un intento por demostrar su crítica u oposición a la integración europea. En efecto, el grado de euroescepticismo de los partidos políticos de los diputados está vinculado con diferentes tendencias de comportamiento político.

Entre los casos aislados de «filibusterismo parlamentario» a través de cientos de intervenciones irrelevantes en el Pleno o de obstruccionismo a la Comisión a través de miles de 'nuisance questions', por un lado, y de la absoluta inactividad y total apatía, por otro, descubrimos que el euroescéptico «medio» encontró diferentes estrategias para mostrar sus posturas contrarias a la integración.

En su accionar en el PE el diputado euroescéptico mostró una fuerte tendencia a controlar las demás instituciones europeas, más que sus colegas pro-europeos, quienes no ocuparon su tiempo en interrogar a los ministros 
en el Consejo o a los Comisarios, de quienes, usualmente, son compañeros de partido. De forma evidente, para el diputado euroescéptico en el PE las competencias de control resultaron ser un instrumento eficaz a la hora de requerir información y mostrar su oposición a la UE, enfocándose en aspectos tales como los costos de la estructura institucional, los supuestos casos de corrupción o el uso de fondos europeos.

Pero los euroescépticos no lograron asumir un papel activo en el trabajo regular de las comisiones parlamentarias, considerado como algo secundario por muchos de ellos, especialmente los más radicales. Ello se reflejó en el bajo número de rapports que les fueron asignados. Por lo tanto, la presencia de estos diputados en las comisiones no pudo ser extrapolada a la promoción de sus ideas sobre Europa. Especialmente sobre temas delicados, los riesgos son demasiado grandes para que diputados anti-UE redacten un informe que termine siendo inaceptable para el resto de los diputados.

A su vez, la baja asiduidad al Pleno que caracterizó a los diputados euroescépticos a lo largo de las cuatro legislaturas también los perjudicó: al no participar tan activamente de las votaciones, estos diputados menoscabaron aún más su influencia en la toma de decisiones del PE. Ya sea interpretado como una estrategia motivada por una falta de interés en el mandato o por un rechazo absoluto a participar de las actividades diarias de la institución, la baja asistencia fue un rasgo característico de estos diputados.

Más allá de estos rasgos en común, euroescépticos 'duros' y 'blandos' exhibieron algunas tendencias de conducta diferentes en el PE. Los euroescépticos 'blandos' concibieron y llevaron adelante su mandato básicamente para cumplir con las funciones legislativas y de control al «ejecutivo» de la UE. Estuvieron interesados en ser ponentes de rapports en las comisiones parlamentarias, pero más aún se comprometieron en la formulación de preguntas escritas y propuestas de resolución. Estos diputados no permanecieron en una oposición «estéril» a la integración europea, sino que intentaron realizar un aporte «constructivo» a través de su trabajo parlamentario.

Los diputados de partidos euroescépticos 'duros', por su parte, se preocuparon por participar en el Pleno, vital para publicitar su oposición frontal al proceso de integración a través de intervenciones orales, marcando las fallas y los efectos negativos de la integración. La lógica implicaba «des-legitimizar» la institución desde dentro, a través de discursos públicos en sesión plenaria. Pero quedaron marginados de la elaboración de rapports. La escasez de informes presentados por estos diputados - especialmente aquéllos de extrema derecha - resultó de la combinación de una libre elección de estos diputados, quienes prefirieron mantenerse al margen de este tipo de actividades vinculadas a las funciones legislativas del PE, así como de una actitud del resto de los diputados, que dispusieron una especie de «cordon sannitaire». 
A su vez, los diputados euroescépticos más radicales tuvieron un promedio de propuestas de resolución muy bajo: portando una posición hostil $\mathrm{y}$ «de principio» respecto de la integración europea tal como está concebida en la UE, para estos diputados las instituciones y políticas europeas eran consideradas antidemocráticas e ilegítimas, y su reforma se tornaba irrelevante. Las propuestas de resolución tampoco constituyeron un instrumento de comunicación atractivo para estos euroescépticos en su afán por defender sus perspectivas antagonistas.

En general, en el PE las acciones de los euroescépticos estaban restringidas por el contexto institucional a determinados tipos de acción porque, por un lado, eran una minoría cuyos puntos de vista no tenían ninguna posibilidad de prevalecer y, por otro lado, porque los demás diputados no esperaban que los euroescépticos estuviesen involucrados en las actividades de la institución. Los diputados euroescépticos estuvieron en el PE «tironeados» por infinidad de fuerzas: las limitaciones institucionales formales, las restricciones informales como el «ostracismo» impuesto en muchos casos por los demás eurodiputados, sus propias limitaciones por su escaso número y el tamaño pequeño de sus agrupaciones, así como por su dificultad para cooperar con otros diputados y para alcanzar consensos con partidos de otras ideologías, y, más importante aún, la tremenda paradoja interna que sufren al pertenecer a una institución que desprecian y cuyas bases de legitimidad desafían.

En la Octava Legislatura, la proporción de diputados anti-integración creció de manera significativa, a diferencia de las anteriores legislaturas. El porcentaje de euroescépticos se amplió, especialmente por el incremento en el número de diputados de dos grupos euroescépticos: el EFDD y el ECR. Sin embargo, no se conformó un grupo político euroescéptico 'duro' de extrema derecha, quedando esos diputados, en su mayoría, como 'no inscritos', y por lo tanto, excluidos de la dinámica política del PE.

Si bien, entonces, la cantidad de euroescépticos aumentó respecto al total de eurodiputados, la imposibilidad de los partidos de extrema derecha anti-UE de conformar un grupo político, por un lado, y las enormes diferencias entre euroescépticos 'blandos' y 'duros', que no logran actuar como bloque, disminuyen sus oportunidades de ejercer alguna influencia real. Sin embargo, el hecho de que el tercer grupo más grande sea el de los Conservadores británicos y sus aliados permite presagiar una legislatura complicada para los grupos mayoritarios, especialmente para aprobar algún tipo de legislación que apoye el avance o la profundización de la integración.

A diferencia de la mayoría de los especialistas sobre el PE, quienes han desdeñado el estudio de las fuerzas opositoras a su interior para concentrarse en otros asuntos, nuestra investigación se ha enfocado justamente en el estudio del comportamiento de los representantes de partidos euroes- 
cépticos. Este análisis resulta vital en un momento donde la UE está atravesando una de las crisis más graves de su historia, y donde el euroescepticismo aparece como un fenómeno instalado y permanente en la integración, que, lejos de constituir un «tabú», se transforma en un elemento fundamental del proceso.

\section{Bibliografía}

ABELLÁN, L., «Marine Le Pen se queda sin grupo propio en el Parlamento Europeo», ElPais.com 24.06.2014 http://internacional.elpais.com/internacional/2014/06/24/actualidad/1403635508_955710.html (última consulta: 01/07/2014).

ALMEIDA, D., «Europeanized Eurosceptics? Radical Right Parties and European Integration», Perspectives on European Politics and Society, Vol. 11, No. 3/2010, pp. 237-253.

ALVAREZ, M.V., «El euroescepticismo en una Unión Europea en crisis: ¿viejo fenómeno en nuevas odres?», Revista Integración y Cooperación Internacional, No. 13/2012, pp. 4-17.

BALE, T., HANLEY, S., SZCZERBIAK, A., «'May Contain Nuts'? The Reality behind the Rhetoric Surrounding the British Conservatives' New Group in the European Parliament», The Political Quarterly, Vol. 81, No. 1/2010, pp. 85-98.

BENEDETTO, G., «Explaining the failure of Euroscepticism in the European Parliament», en SZCZERBIAK, A. y TAGGART P. (eds.), Opposing Europe? The Comparative Party Politics of Euroscepticism, Volume 2 Comparative and Theoretical Perspectives, Oxford University Press, Oxford, 2008, pp. 127-150.

BRACK, N., «Eurosceptics in the European Parliament: Exit or Voice?», Journal of European Integration, Vol. 34, No. 2/2012, pp. 151-168.

BRACK, N., «Euroscepticism at the Supranational Level: The Case of the 'Untidy Right' in the European Parliament», Journal of Common Market Studies, Vol. 51, No. 1/2013, pp. 85-104.

BRACK, N. y COSTA, O., «The Role(s) of the Eurosceptic MEPS», en FUCH, D., MAGNI-BERTON, R. y ROGER, A. (eds.), Euroscepticism: Images of Europe among Mass Publics and Political Elites, Barbara Budrich Publishers, 2009.

CORBETT, R.; JACOBS, F. y SHACKLETON, M., The European Parliament, John Harper Publishing, Londres, 2011 (1990).

EVANS, A. M. y VINK, M. P., «Measuring group switching in the European Parliament: Methodology, data and trends (1979-2009)», Análise Social, Vol. XLVII (1. $\left.{ }^{\circ}\right)$, No. 202/2012.

FARIZA, I. «Los eurófobos reconstruyen su grupo en el Parlamento Europeo», Elpais.com, 21.10.2014, http://internacional.elpais.com/internacional/2014/10/20/ actualidad/1413820636_708250.html (última consulta: 22/10/2014).

FERRER, I. «La ultraderecha europea sella una alianza». ElPais.com 13.11.2013. http:// internacional.elpais.com/internacional/2013/11/13/actualidad/1384343925_371743. html (última consulta: 21/12/2013). 
FLOOD, C., «Euroscepticism: A Problematic Concept». Trabajo presentado en la UACES 32nd Annual Conference and 7th Research Conference, Queen's University Belfast, Septiembre 2002.

GAGATEK, W., «British Conservative Party and the Group of the European People's Party - European Democrats in the European Parliament - an analysis of the history and present shape of difficult relationships», Międzynarodowy Przeglqd Polityczny (6)/2004, pp. 162-182.

GÓMEZ-REINO, M., «Las elecciones europeas de 2009 y el espectro de la extrema derecha», ARI 101/2009, Madrid: Real Instituto Elcano.

HIX, S., «Dimensions and alignments in European Union politics: Cognitive constraints and partisan responses», European Journal of Political Research, No. 35/1999, pp. 69-125.

HIX, S., «Legislative Behaviour and Party Competition in the European Parliament: An Application of Nominate to the EU», Journal of Common Market Studies, Vol. 39, No. 4/2001, pp. 663-688.

HIX, S. y NOURY, A., «After Enlargement: Voting Patterns in the Sixth European Parliament», Legislative Studies Quarterly, Vol. 34, No. 2/2009, pp. 159-174.

HIX, S.; NOURY, A. y ROLAND, G., Democratic Politics in the European Parliament, Cambridge University Press, Cambridge, 2007.

HIX, S.; RAUNIO, T. y SCULLY, R., «Fifty Years On: Research on the European Parliament», Journal of Common Market Studies, Vol. 41, No. 2/2003, pp. 191202.

HOOGHE, L. y MARKS, G., «Sources of Euroscepticism», Acta Politica, 42/2007, pp. 119-127.

JUDGE, D. y EARNSHAW, D., The European Parliament, Palgrave Macmillan, Basingstoke, 2003.

KREPPEL, A., The European Parliament and Supranational Party System. A Study in Institutional Development. Cambridge University Press, 2002.

LECONTE, C., Understanding Euroscepticism, Palgrave Macmillan, Basingstoke, 2010.

LLAUDES, S. «Elecciones al Parlamento Europeo: ¿y ahora qué?», Comentario Elcano 39/2014-3/6/2014.

McELROY, G. y BENOIT, K., «Policy positioning in the European Parliament», European Union Politics, Vol. 13 No. 1/2011, pp. 150-167.

MORRIS, M., Conflicted Politicians: the populist radical right in the European Parliament, Counterpoint, Londres, 2013.

NOURY, A., «Ideology, Nationality, and Euro-Parliamentarians», European Union Politics, No. 3/2002, pp. 33-58.

PARLAMENTO EUROPEO, Resultados de las elecciones 2014, http://www.resultados-elecciones2014.eu/es/turnout.html (última consulta: 14/08/2014).

PROKSCH, S. y SLAPIN, J.B., «Parliamentary questions and oversight in the European Union», European Journal of Political Research, Vol. 50, No. 1/2011, pp. 53-79.

RAUNIO, T., «Political parties in the European Union», en JØRGENSEN K. E., POLLACK, M. A. y ROSAMOND, B. (eds.), Handbook of European Union Politics, Sage Publications, Londres, 2007. 
RAY, L., «Mainstream Euroscepticism: Trend or Oxymoron?», Acta Politica, 42/2007, pp. 153-172.

REIF, K. y SCHMITT, H., «Nine Second-Order Elections: A Conceptual Framework for the Analysis of European Election Results», European Journal of Political Research, Vol. 8, No. 1/1980, pp. 3-44.

SCHMITT, H., «The Nature of European Issues: Conceptual Clarifications and Some Empirical Evidence», en DE VREESE, C., SCHMITT, H., (eds.): A European Public Sphere: How much of it do we have and how much do we need?, Mannheim, 2007, pp. 11-22.

SCULLY, R., «Between Nation, Party and Identity: a Study of European Parliamentarians», EPRG Working Paper, No. 5/1999, pp. 1-25.

STARTIN, N., «Where to for the Radical Right in the European Parliament? The Rise and Fall of Transnational Political Cooperation», Perspectives on European Politics and Society, Vol. 11 No. 4/2010, pp. 429-449.

SZCZERBIAK, A. y TAGGART, P., «Opposing Europe: Party Systems and Opposition to the Union, the Euro and Europeanisation», SEI Working Paper N. 36 Opposing Europe Research Network Working Paper No. 1/2000.

SZCZERBIAK, A. y TAGGART, P., «Theorising Party-Based Euroscepticism: Problems of Definition, Measurement and Causality», SEI Working Paper No. 69 - European Parties Elections and Referendums Network Working Paper No. 12/2003.

SZCZERBIAK, A. y TAGGART, P., «Introduction: Researching Euroscepticism in European Party Systems: A Comparative and Theoretical Research Agenda», en SZCZERBIAK, A. y TAGGART P. (eds.), Opposing Europe? The Comparative Party Politics of Euroscepticism Volume 2 Comparative and Theoretical Perspectives, Oxford: Oxford University Press, 2008, pp. 1-27.

USHERWOOD, S. y STARTIN, N., «Euroscepticism as a Persistent Phenomenon», Journal of Common Market Studies, Vol. 51, No. 1/2013, pp. 1-16.

VASILOPOULOU, S., "Varieties of Euroscepticism: The Case of the European Extreme Right», Journal of Contemporary European Research, Vol. 5, No. 1/ 2009, pp. 3-23. 